\section{"Do Marajó ao Arquivo" como revelação do universalismo amazônico de Benedito Nunes}

\author{
Por Márcio Benchimol Barros \\ Universidade Estadual Paulista Júlio de Mesquita Filho, \\ Campus Marília \\ (benchimolbarros@gmail.com)
}

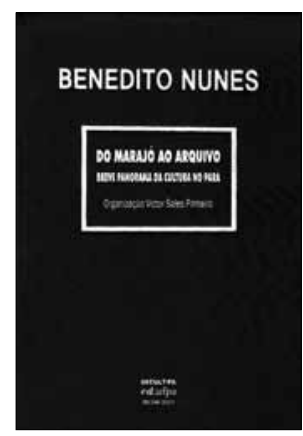

NUNES, Benedito

Do Marajó ao arquivo:

breve panorama da cultura no Pará.

Org. Victor Sales

Pinheiro. Belém:

EDUFPA/SECULT,

2012. 496 p. ISBN 97885-2470-515-1

"Do Marajó ao arquivo: breve panorama da cultura no Pará" chama-se o alentado volume publicado no ano de 2012 pela Editora da Universidade Federal do Pará (EDUFPA) em colaboração com a Secretaria de Cultura do Estado do Pará (SECULT), em homenagem ao saudoso professor Benedito Nunes, fundador do Departamento de Filosofia daquela universidade e falecido em fevereiro de 2011. Informa-nos Paulo Chaves Fernandes, Secretário de Cultura do Pará, em seu texto de apresentação, que estamos, na verdade, diante da realização - infelizmente, póstuma - de projeto mais antigo, idealizado pelo organizador da obra, professor Victor Sales Pinheiro. Pretendia este, depreende-se do texto mencionado, fazer publicar, pela EDUFPA, uma coletânea de textos de Benedito Nunes das mais variadas naturezas e destinações, que fosse capaz de revelar algo daquilo que Fernandes chama, justificadamente, de "o pensamento amazônico" do homenageado.

De fato, contém o volume variadíssima coleção de oitenta e um pequenos escritos de Nunes, datados entre 1952 e 2011, alguns deles inéditos, como "Crônica de uma Academia", sobre a tentativa do jovem Benedito de, juntamente com colegas, entre eles Haroldo Maranhão, fundar uma Academia de Letras em Belém, aos moldes da Academia Brasileira de Letras, como também um curto texto sobre o artista plástico Antar Rohit. São artigos uns publicados em periódicos ou livros acadêmicos, outros em jornais -, discursos, apresentações de obras literárias, prefácios, entrevistas, 'orelhas' de livros e ainda textos de outros formatos, precedidos por dois escritos de apresentação - sendo o primeiro aquele aludido mais acima e o segundo assinado pelo reitor da Universidade Federal do Pará (UFPA) -, um artigo introdutório, intitulado "O universalismo de Benedito Nunes", de autoria de Sales Pinheiro, e mais um texto de Nunes, com título de "Da caneta ao computador", no qual uma breve autobiografia intelectual dá natural ensejo a considerações gerais sobre as relações entre poesia e filosofia. Apesar da variedade temática dos textos de Benedito Nunes aqui reunidos - como também da multiplicidade de intenções com que foram concebidos e, correspondentemente, dos estilos literários adotados pelo autor -, eles guardam entre si um traço comum, que dá clara unidade à coletânea: a referência sempre presente à região amazônica, seja na forma de reflexões filosoficamente inspiradas sobre sua história política e cultural, seja na apreciação crítica da obra de seus mais destacados artistas, especialmente no campo da literatura, mas também incluindo os domínios da música, da arquitetura e das demais artes plásticas. Uma quase exceção é representada pelo discurso proferido por Nunes por ocasião do quinto aniversário da Faculdade de Filosofia, Ciências e Letras da UFPA (apesar da motivação local e das referências iniciais ao momento por que passava a faculdade, o pensamento de Nunes logo se dirige ao plano das ideias e à história da filosofia). Assim sendo, pode-se dizer com tranquilidade que a obra, de fato, revela o pensamento amazônico do professor Nunes, e seu mérito mais evidente é precisamente o de reunir em um único volume tantos escritos em que 
temas importantes relativos à região são tratados por um dos intelectuais de maior relevo já por ela produzidos.

Insistir, contudo, no elemento local desses escritos seria desconhecer o outro lado da intenção de Sales Pinheiro, expresso no título de seu ensaio introdutório. Trata-se não somente de pôr em destaque a face regional da atividade intelectual de Nunes, mas também de realçar, ao mesmo tempo, o caráter universalista deste pensamento, que, longe de entrar em contradição com o interesse pelo especificamente amazônico, informa e dá consistência a reflexões neste campo, elevando-as a um patamar nunca dantes alcançado. Duas coisas, com efeito, nos revela a leitura dos textos compilados: primeiramente, que há um envolvimento profundamente pessoal do autor com os temas tratados. Benedito Nunes não aborda a história e a tradição artístico-cultural da Amazônia como objetos de estudo estranhos a si mesmo. Percebe-se, antes, uma identificação afetiva e intelectual profunda do autor com os objetos analisados; vê-se que seus contatos com tais objetos foram nada menos que determinantes de sua formação como ser humano e como pensador, e suas reflexões sobre eles são inseparáveis de sua própria autoconsciência como intelectual. Falar da arte e da história cultural da Amazônia é, para Nunes, na verdade, uma forma de busca de si mesmo, funcionando como extensão e complemento de sua autobiografia intelectual.

Por outro lado, percebe-se claramente que tais temas são abordados sob o signo do universal, pois que são referidos constantemente à tradição filosófica e artístico-literária do Ocidente. Ao debruçar-se sobre a arte e a história de sua região, Benedito Nunes não deixa de ser o ensaísta filosófico, o historiador da filosofia e o crítico literário, cujo valor se vê reconhecido tanto nacional como internacionalmente; mas, antes, mostra outra faceta de sua atividade crítico-filosófica. Precisamente, a junção entre profunda identificação pessoal e o distanciamento naturalmente exigido pela reflexão crítico-filosófica nos dá a exata medida da contribuição do autor à cultura amazônica, pois a identificação afetiva e existencial com a região também é traço característico dos artistas analisados por Benedito Nunes, e não há como negar que a obra de um Dalcídio Jurandir ou um Max Martins também alcança a universalidade, pois fala e é significativa também para aqueles a quem falta tal identificação. Mas esta universalidade tem um limite: a arte se realiza na produção do objeto artístico, e este vem, necessariamente, reclamar ainda a intervenção da reflexão crítica e distanciada, única capaz de pôr de manifesto sua inserção no contexto universal da história da arte e esclarecer suas relações com a arte de outros tempos e lugares. A ciência, por outro lado, já produziu, e continua a produzir, um volume cada vez mais crescente de conhecimentos sobre nossa região, conhecimentos estes também dotados de valor universal. A exigência da pura objetividade científica, porém, exclui, por sua natureza, a identificação afetiva e pessoal com o objeto estudado. Seu discurso é sempre o do sujeito que se distingue claramente de seu objeto, sua voz é sempre a voz impessoal do conhecimento objetivo. Decerto, tolera-se (e mesmo admira-se) que a sóbria elocução científica ceda lugar, aqui e ali, a irrupções subjetivas ou a considerações que ultrapassam os limites ou o escopo da ciência. A linguagem do cientista resvala, muitas vezes, no literário ou no filosófico, mas essa flexibilidade é imediatamente paga ao preço da momentânea renúncia àquilo que a deve caracterizar, nomeadamente, à objetividade científica. Já a dicção de Nunes é essencialmente filosófica e essencialmente literária: filosofa ao falar de filosofia e torna-se artística ao falar de arte; mas também se veste das galas da literatura ao falar de filosofia, e torna-se filosófica ao falar de arte. Por isso, nela podem ter voz tanto o apego subjetivo e pessoal ao solo natal quanto o livre voo especulativo da razão, que vemos tantas vezes maravilhosamente combinados nos textos reunidos em "Do Marajó ao arquivo". Nestes, assistimos ao constante esforço do local por refletir-se no vasto espelho do universal, mas também surpreendemos o universal a deitar amoroso olhar sobre o local. Não se trata, pois, simplesmente, de um autor a falar de temas 
da história e cultura da Amazônia, mas, sinto-me tentado a dizer, é a própria Amazônia que, em Benedito Nunes, toma consciência de si e busca determinar seu lugar no campo da cultura ocidental.

Se me for permitido retocar a frase de Fernandes, diria que "Do Marajó ao arquivo" revela não tanto o pensamento amazônico de Benedito Nunes, mas principalmente o próprio Nunes, como pensador amazônico. É um grande serviço prestado aos admiradores do mestre desparecido, pois aqueles que o conhecem apenas por seus trabalhos em historiografia filosófica ou como crítico literário (certamente, a grande maioria), desconhecem esta faceta de seu talento ou a conhecem apenas de forma fragmentária. É nestes textos menores, e muitas vezes despretensiosos, que se revela mais fortemente esse aspecto de Nunes. Tais textos haveriam de permanecer dispersos entre as páginas de publicações acadêmicas maiores, de jornais e nas estantes dos apreciadores da boa prosa e poesia paraense, não fora a existência de um arquivo bem organizado, mantido pelo próprio Nunes, e a iniciativa de Sales de compilá-los em um só volume. Mas, por outro lado, o admirador de Nunes que lhe descobre essa face amazônica em "Do Marajó ao arquivo" há de ali reencontrar o mesmo intelectual que já conhecia dos ensaios filosóficos e crítico-literários, pois filosofia e crítica literária são, como já destacado, os dois pilares que sustentam sua visão da história e cultura amazônicas, tornando-a tão singular. Trata-se, pois, de mais um elemento da personalidade filosófica de Benedito Nunes que aqui se adensa e ganha contorno, unindo-se aos que são mais familiares a seus leitores. Esta imagem ainda se enriquece pela multiplicidade dos estilos literários aqui dominados pelo mestre. Ao sóbrio rigor de sua prosa filosófica e ao refinamento literário de sua crítica estética, vêm aqui somar-se a espontaneidade informal e o tom por vezes nostálgico-confessional de quem fala a amigos confidentes de coisas queridas e tão próximas de si, a ponto de suas histórias confundirem-se com a própria história do falante. Assim, a partir do jogo caleidoscópico que "Do Marajó ao arquivo" nos propõe, vamos aprendendo a formar a imagem completa de uma mesma personalidade intelectual, a espelhar-se diante de nós em multicolorida multiplicidade.

Creio que uma homenagem póstuma a um intelectual da altura de Benedito Nunes alcança seu objetivo não exatamente rememorando uma existência que findou, mas, antes, proclamando uma necessária presença no dia de hoje e no de amanhã. Mais ainda, como é o caso em "Do Marajó ao arquivo", se ajuda a criar essa presença, a tornar visível, no presente e no futuro, aquele a quem se homenageia, em toda a amplitude de sua atividade como intelectual. Isso é, sem dúvida, realizado por esta coletânea, que tive o prazer de resenhar e que tomo como dever recomendar a leitura a todos que se interessarem não apenas por assuntos da história e da cultura amazônicas, mas também pela obra de um dos principais representantes de ambas.

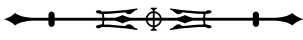


